\title{
Associations of education and work status with alcohol use and cessation among pregnant women in Japan: the Tohoku Medical Megabank Project Birth and Three-Generation Cohort Study
}

Keiko Murakami ( $\nabla$ mkeiko-tky@umin.ac.jp )

Tohoku Medical Megabank Organization, Tohoku University https://orcid.org/0000-0003-2103-4106

Taku Obara

Tohoku Daigaku Byoin Rinsho Kenkyu Suishin Center

Mami Ishikuro

Tohoku Daigaku Byoin Rinsho Kenkyu Suishin Center

Fumihiko Ueno

Tohoku Daigaku Global Learning Center

Aoi Noda

Tohoku University

Shinichi Kuriyama

Tohoku University

Research article

Keywords: alcohol cessation, alcohol use, early pregnancy, Japan, middle pregnancy, pregnant women, prospective cohort study

Posted Date: December 3rd, 2020

DOI: https://doi.org/10.21203/rs.3.rs-40323/v2

License: (c) (1) This work is licensed under a Creative Commons Attribution 4.0 International License.

Read Full License

Version of Record: A version of this preprint was published at BMC Public Health on July 15th, 2021. See the published version at https://doi.org/10.1186/s12889-021-11461-w. 


\section{Abstract}

Background: There is inconsistent evidence on the associations of education and work status with alcohol use during pregnancy. We aimed to examine the associations of education and work status with alcohol use in early and middle pregnancy and alcohol cessation between early and middle pregnancy in Japan.

Methods: This prospective study was part of the Tohoku Medical Megabank Project Birth and ThreeGeneration Cohort Study from 2013 to 2017. Pregnant women were recruited at approximately 50 obstetric clinics and hospitals in Miyagi Prefecture in Japan. We analyzed 11592 pregnant women who completed the questionnaires administered in early pregnancy and middle pregnancy. Women were dichotomized as current drinkers or non-drinkers in both early and middle pregnancy. Multivariable logistic regression analyses were conducted to examine associations of education and work status with alcohol use in early and middle pregnancy, adjusting for age, income, psychological distress, and work status/education. Associations with alcohol cessation between early pregnancy and middle pregnancy were also examined.

Results: Prevalence of alcohol use in early and middle pregnancy was $20.9 \%$ and $6.4 \%$, respectively. Higher education was associated with alcohol use in early pregnancy and alcohol cessation during pregnancy; the odds ratios (ORs) of $\geq$ university education compared with $\leq$ high school education were 1.47 (95\% confidence interval [Cl], 1.30-1.66) and 1.31 (95\% Cl, 1.00-1.71), respectively. Work status was associated with alcohol use in both periods and alcohol cessation during pregnancy; for alcohol cessation, the OR of working in early pregnancy only compared with not working in both periods was 1.72 $(95 \% \mathrm{Cl}, 1.03-2.88)$.

Conclusions: Women with higher education were more likely to consume alcohol in early pregnancy and to cease between early pregnancy and middle pregnancy. Working women were more likely to consume alcohol throughout pregnancy in Japan.

\section{Background}

Alcohol is a teratogen that can readily cross the placenta, which results in damage to the brain and other organs of the developing embryo and fetus. Alcohol use during pregnancy can cause pregnancy complications such as low birth weight, preterm birth, and small for gestational age $[1,2]$, and can result in a range of lifelong physical, behavioral, and intellectual disabilities known as fetal alcohol spectrum disorders [2,3]. Because no amount of alcohol and no time to drink can be considered safe during pregnancy [2,4], recommendations for alcohol use during pregnancy advocate abstinence in most countries [5]. Despite such recommendations, the global prevalence of alcohol use during pregnancy was estimated at $9.8 \%[6]$.

Identification of pregnant women who are most likely to consume alcohol is essential for targeted interventions. Although a wide range of social factors have been examined as potential predictors, there 
is inconsistent evidence on the associations of education and work status with alcohol use during pregnancy [7]. It is possible that some of the inconsistent findings may be explained by different timings in the assessment of alcohol use and different social and cultural contexts across countries.

Most studies examining alcohol use have been conducted using postpartum retrospective reports or at only one time point during pregnancy. Retrospective reports on postpartum women are subject to imprecise estimates of when they ceased alcohol use during pregnancy [8]. Differences in prevalence of alcohol use have been reported between early pregnancy and middle/late pregnancy [9-14]. Although this suggests that the associations of education and work status with alcohol use may differ by pregnancy stage, very few studies have been conducted at different points during pregnancy among women who had already become aware of their pregnancy [15-17]. Furthermore, to our knowledge, the association between changes in work status during pregnancy and alcohol cessation has never been examined.

Social and cultural contexts influence varying social patterns of alcohol use in different countries [18]. There are two characteristics of alcohol use in Japan. One is that there are many opportunities to inform pregnant women of the health risks of alcohol use from very early pregnancy, including the distribution of maternal and child health handbooks as soon as pregnancy is confirmed, and health checkups for all pregnant women $[19,20]$. The other is that there is the custom of drinking with work colleagues because alcohol use is often an integral part of social life [21,22]. One national survey regarding alcohol use among Japanese women have shown that working women were associated with a higher risk of harmful alcohol use [22]. It is therefore possible that these characteristics can affect the associations of education and work status with alcohol use among pregnant women in Japan.

Considering these circumstances, we aimed to examine the associations of education and work status with alcohol use in early and middle pregnancy and alcohol cessation between early and middle pregnancy in Japan, where women originally had low alcohol use rate but this rate has been increasing recently [23].

\section{Methods}

Study population

Data were obtained from the Tohoku Medical Megabank Project Birth and Three-Generation Cohort Study (TMM BirThree Cohort Study), which has been described elsewhere [24]. The aim of this cohort study was to evaluate the complex interactions of genetic and environmental factors using information on in utero and subsequent pediatric exposures, and about maternal, pediatric, and family outcomes by evaluating a birth cohort and members of three generations [24]. Pregnant women and their family members were contacted in obstetric clinics or hospitals when they scheduled their deliveries from 2013 to 2017. Approximately 50 obstetric clinics and hospitals in Miyagi Prefecture participated in the recruitment process. Tohoku University Tohoku Medical Megabank Organization established seven community support centers in Miyagi Prefecture as local facilities for voluntary admission-type recruitment and health assessment of the participants [25]. Trained genome medical research coordinators were placed in 
each clinic, hospital, or community support center to provide information on the TMM BirThree Cohort Study to potential participants and to receive signed informed consent forms from those who agreed to participate. Of 32986 pregnant women who were contacted, 22493 agreed to participate and 20879 completed the questionnaires in early pregnancy ( $<14$ weeks of gestation) and middle pregnancy (14-27 weeks of gestation). Among them, 9287 women were excluded because of missing values in equivalent household income, work status, psychological distress, alcohol use, or educational attainment. The remaining 11592 pregnant women were included in the present study. Figure 1 shows the flow diagram of the present study. The TMM BirThree Cohort Study protocol was reviewed and approved by the Ethics Committee of Tohoku University Tohoku Medical Megabank Organization (2013-1-103-1). The characteristics of 11592 analyzed women and 9287 excluded women are shown in Supplementary Table 1.

Measures

Educational attainment was categorized into three groups: high school or lower (elementary, junior high school, or senior high school), college (2-year college or special training school), and university or higher (university or graduate school). Women were asked how many days per week they worked during early and middle pregnancy, and a response of $>0$ days was defined as working. Changes in work status during pregnancy was categorized as not working in early and middle pregnancy, working in early pregnancy only, and working in both early and middle pregnancy.

Women were asked to choose one of the following response options for alcohol use in early and middle pregnancy: current drinker, past drinker, never drinker, and constitutionally never drinker. Alcohol use in the present study was defined as response "current drinker" based on the idea that there is no known safe amount of alcohol to drink during pregnancy $[2,4]$. Alcohol cessation between early and middle pregnancy was defined as alcohol use in early pregnancy, but not in middle pregnancy.

As covariates, we chose age, income, and psychological distress [7]. Age in early pregnancy was categorized into three groups: $\leq 29,30-34$, and $\geq 35$ years. Women were asked to select their total annual household income among seven categories: $<2,2-4,4-6,6-8,8-10,10-12$, and $>12$ million Japanese yen. Equivalent household income was calculated as the household income divided by the square root of the number of family members [26], and categorized into four groups: $<2,2-3,3-4$, and $>4$ million Japanese yen, which nearly corresponded to quartiles. In early and middle pregnancy, women provided responses to the Japanese version of the $\mathrm{K} 6$ scale, consisting of six items for assessment of depressive moods and anxiety during the past 30 days. Responses ranged from 0 (none of the time) to 4 (all of the time), with total scores ranging from 0 to $24[27,28]$. Psychological distress was defined as scores $\geq 5$ $[28,29]$. Changes in psychological distress during pregnancy was categorized as none in early and middle pregnancy, in early pregnancy only, in middle pregnancy only, and in both early and middle pregnancy.

Statistical analysis 
Multivariable logistic regression analyses were conducted to examine the associations of education and work status with alcohol use in early pregnancy and alcohol use in middle pregnancy. In each pregnancy period, we calculated the age-adjusted odds ratio (OR) and 95\% confidence interval (CI) of education and work status. We made further adjustments for income, psychological distress, and work status/education. To examine the associations of education and work status with alcohol cessation among women who consumed alcohol in early pregnancy, we calculated the age-adjusted OR and $95 \% \mathrm{Cl}$ of education and changes in work status during pregnancy. We made further adjustments for income, changes in psychological distress during pregnancy, and changes in work status during pregnancy/education. As there is evidence of socioeconomic interactions with the effect of work status on alcohol use in women [30], we also stratified our models by work status or education and examined whether it modified the associations by including interaction terms in the models.

All analyses were conducted with SAS version 9.4 software (SAS Institute Inc., Cary, NC). For all analyses, a two-tailed $P$ value $<0.05$ was considered statistically significant.

\section{Results}

Characteristics of participants

Table 1 shows the characteristics of the pregnant women. About 30\% of women had graduated from university or higher. Prevalence of working in early and middle pregnancy was $66.0 \%$ and $61.4 \%$, respectively. Prevalence of alcohol use in early and middle pregnancy was $20.9 \%$ and $6.4 \%$, respectively.

Associations of education and work status with alcohol use in early pregnancy

Table 2 presents the prevalences, ORs, and 95\% Cls for alcohol use in early pregnancy. Higher educational attainment was associated with an increased risk of alcohol use in early pregnancy; the multivariableadjusted OR of college education and that of $\geq$ university education with $\leq$ high school education were $1.33(95 \% \mathrm{Cl}, 1.18-1.49)$ and 1.47 (95\% Cl, 1.30-1.66). Working in early pregnancy was associated with an increased risk of alcohol use in early pregnancy; the multivariable-adjusted OR of working compared with not working was $1.53(95 \% \mathrm{Cl}, 1.38-1.70)$. Higher equivalent household income was associated with an increased risk of alcohol use in early pregnancy, while age and psychological distress in early pregnancy were not associated with alcohol use in early pregnancy. Supplementary Table 2 shows the results of stratified analyses by work status or education. The association of education was found regardless of work status, and the association of work status was found regardless of education (interaction $P=0.070)$.

Associations of education and work status with alcohol use in middle pregnancy

Table 3 presents the prevalences, ORs, and 95\% Cls for alcohol use in middle pregnancy. Educational attainment was not associated with alcohol use in middle pregnancy; the multivariable-adjusted OR of college education and that of $\geq$ university education with $\leq$ high school education were $1.06(95 \% \mathrm{Cl}$, 
$0.88-1.27)$ and $0.95(95 \% \mathrm{Cl}, 0.77-1.17)$. Working in middle pregnancy was associated with an increased risk of alcohol use in middle pregnancy; the multivariable-adjusted OR of working compared with not working was $1.38(95 \% \mathrm{Cl}, 1.18-1.63)$. Higher age and psychological distress in middle pregnancy were associated with an increased risk of alcohol use in middle pregnancy, while equivalent household income was not associated with alcohol use in middle pregnancy. Supplementary Table 3 shows the results of stratified analyses by work status or education. No association of education was found regardless of work status, and no association of work status was found among women with $\geq$ university education (interaction $P=0.030$ ).

Associations of education and work status with alcohol cessation between early and middle pregnancy

Table 4 presents the prevalences, ORs, and $95 \%$ Cls for alcohol cessation between early and middle pregnancy among women who consumed alcohol in early pregnancy. The prevalence of alcohol cessation was $77.7 \%$. Higher educational attainment was associated with alcohol cessation; the multivariable-adjusted OR of college education and that of $\geq$ university education with $\leq$ high school education were $1.16(95 \% \mathrm{Cl}, 0.91-1.49)$ and $1.31(95 \% \mathrm{Cl}, 1.00-1.71)$. Working in early pregnancy only was associated with alcohol cessation; the multivariable-adjusted OR of working in early pregnancy only compared with not working in both periods was $1.72(95 \% \mathrm{Cl}, 1.03-2.88)$. Working in both periods was not associated with alcohol cessation; the corresponding OR was 1.09 (95\% Cl, 0.87-1.36). Higher equivalent household income was associated with alcohol cessation, while age and psychological distress were not associated with alcohol cessation. Supplementary Table 4 shows the results of stratified analyses by work status or education. The association of education was found only among working women, and the association of work status was found only among women with $\geq$ college education (interaction $P=0.012$ ).

\section{Discussion}

The present study examined the associations of education and work status with alcohol use in early and middle pregnancy and alcohol cessation between early and middle pregnancy in Japan. Prevalence of alcohol use decreased from $20.9 \%$ in early pregnancy to $6.4 \%$ in middle pregnancy. Women with higher education were more likely to consume alcohol in early pregnancy, but were more likely to cease between early and middle pregnancy especially among working women. Working women were more likely to consume alcohol in early and middle pregnancy, and women who worked in early pregnancy but not middle pregnancy were more likely to cease between early and middle pregnancy. Higher age, higher income, and psychological distress were associated with an increased risk of alcohol use during pregnancy.

The prevalence of alcohol use in early pregnancy was $20.9 \%$. We could not directly compare the prevalence of alcohol use in early pregnancy with corresponding data in Japan, because there is little information on alcohol use according to pregnancy stage. The 2013 national survey among the general population of Japan, who may be non-pregnant or pregnant, revealed that women who reported alcohol 
use comprised $79.4 \%$ in their twenties, $77.0 \%$ in their thirties, and $77.9 \%$ in their forties [22]. Previous studies in Japan showed that about half of pregnant women retrospectively reported alcohol use before they became aware of their pregnancy $[9,10,31]$. Taken together, it is assumed that many women in the present study had already ceased drinking when they filled out the questionnaires administered in early pregnancy.

Higher education was associated with an increased risk of alcohol use in early pregnancy when alcohol cessation due to pregnancy awareness had already started. There are several possible explanations for the association between higher education and alcohol use in early pregnancy. First, alcohol use may be more acceptable among women with higher education. Specifically, more years spent in education, improved labor market prospects, increased opportunities for socialization, and delayed pregnancy mean that alcohol use has easily found a place among these women [32]. Second, social networks among highly educated people may increase the risk of alcohol use. Alcohol use can follow social networking paths [33] and highly educated women tend to associate with other highly educated people [34] who are more likely to consume alcohol [35]. Third, highly educated women may have better-paid jobs involving higher degrees of responsibility and stress as well as more chances to go out drinking with male colleagues with higher limits of drinking [36].

Higher education was also associated with alcohol cessation between early and middle pregnancy. There is some evidence that highly educated women were more likely to consume alcohol before becoming aware of their pregnancy, and more likely to continue or reduce rather than cease alcohol use during pregnancy in Western countries $[16,17,37,38]$. Meanwhile, two studies in Japan showed that highly educated women were less likely to consume alcohol after becoming aware of their pregnancy [9,31]. Our finding is consistent with the previous findings in Japan. In Japan, it is mandatory for women to notify the municipal office of their pregnancy as soon as it is confirmed. At the municipal office, they receive maternal and child health handbooks [19] and tickets to use for pregnant woman health checkups at public expense. They also have access to counseling services with public health nurses, mother/parent classes, and various information services [20]. Knowledge on the health risks of alcohol use for the fetus was shown to be associated with a decreased risk of alcohol use during pregnancy [10]. Psychological and educational interventions such as supportive counselling and brief educational sessions were suggested to encourage pregnant women to cease alcohol use [39]. It is possible that highly educated women are more receptive to messages offered during the above opportunities than less educated women, because education conveys factual health-related knowledge and raises cognitive skills that affect health-promoting decisions $[34,40]$. However, early pregnancy is the time of great neurological vulnerability for the fetus $[2,41]$. The message that alcohol can damage a fetus even during the earliest weeks of pregnancy should be spread more widely.

Working was associated with alcohol use in early and middle pregnancy, and working in early pregnancy but not middle pregnancy was associated with alcohol cessation between these periods. The associations between work status and alcohol use during pregnancy are inconsistent [7]; working outside the home was associated with an increased risk of alcohol use during pregnancy $[9,31,42,43]$, while no 
association was found $[44,45]$. One possible explanation for the observed association between working and alcohol use is that working people, who are more likely to have higher income, can afford to purchase alcoholic beverages [36]. However, the present study showed that the association between working and alcohol use remained after adjustment for income. Another possible explanation is that working may increase the opportunity for alcohol use. In Japan, there is a relatively high tolerance of alcohol and drinking is an important event in some working environments. For example, some working people socialize with colleagues after work in drinking meetings [21,22]. Our finding that leaving work between early and middle pregnancy was associated with alcohol cessation between these periods would support this explanation. We also found the interaction between education and work status, which indicated that the association between higher education and alcohol cessation during pregnancy was found only among working women. This may be because women with higher education can decide to modify their behaviors even if they have many opportunities for drinking.

Preconception abstinence from alcohol is preferred but difficult, because a large proportion of women of reproductive age consume alcohol [22] and women do not always plan to get pregnant [46]. It is therefore recommended that pregnant women who have already consumed alcohol during pregnancy should stop to minimize further risk [4]. A national campaign in Japan, the second term of Healthy Parents and Children 21, aims to eradicate alcohol use among pregnant women [47]. However, the present study showed that pregnant women consumed alcohol after becoming aware of their pregnancy: $20.9 \%$ in early pregnancy and $6.4 \%$ in middle pregnancy. For example, World Health Organization recommends screening all women for unhealthy alcohol use before pregnancy and in the first trimester with a validated tool, and offering a brief intervention to all pregnant women who use alcohol [48]. The present study has revealed factors that can be used to identify high-risk subpopulations of pregnant women and can be targeted in future alcohol-prevention interventions.

The present study has several limitations. First, we were able to analyze approximately half of the pregnant women who agreed to participate in the TMM BirThree Cohort Study. Women who were excluded from the analysis were less educated and more likely to be non-drinkers (Supplementary Table 1), which could lead to underestimation of the association between education and alcohol use during pregnancy. Second, the study was conducted in one of the 47 prefectures in Japan, and therefore the generalizability of the present findings is limited. A national survey reported that the prevalences of alcohol use during pregnancy were $4.3 \%$ in $2013,1.6 \%$ in $2015,1.3 \%$ in 2016 , and $1.2 \%$ in 2017 , although these were retrospective reports from mothers after childbirth [47]. Finally, alcohol use was self-reported and this can be a source of uncertainty because women may be influenced by social desirability, a bias that tends to be important when questions deal with socially undesirable attitudes and behaviors. However, the superiority of self-administered questionnaires over face-to-face interviews in measuring alcohol use during pregnancy has been supported [8].

\section{Conclusions}


Women with higher education were more likely to consume alcohol in early pregnancy and to cease between early and middle pregnancy especially among working women, while working women were more likely to consume alcohol throughout pregnancy and women who worked in early but not middle pregnancy were more likely to cease in Japan. Alcohol use during pregnancy is a completely preventable cause of birth defects and developmental disabilities. Our findings indicate that determination of social predictors for alcohol use at different points during pregnancy will be useful for public health interventions to prevent alcohol use among pregnant women.

\section{Abbreviations}

95\% Cl: 95\% confidence interval; OR: odds ratio; TMM BirThree Cohort Study: Tohoku Medical Megabank Project Birth and Three-Generation Cohort Study

\section{Declarations}

Ethics approval and consent to participate

The TMM BirThree Cohort Study protocol was reviewed and approved by the Ethics Committee of Tohoku University Tohoku Medical Megabank Organization (2013-1-103-1). Trained genome medical research coordinators were placed in each clinic, hospital, or community support center to provide information on the TMM BirThree Cohort Study to potential participants and to receive signed informed consent forms from those who agreed to participate.

Consent for publication

There are no details on individual participants within the manuscript.

Availability of data and material

A biobank is being constructed based on the TMM BirThree Cohort Study. Although we ar planning to share the full baseline data by the end of 2020, a portion of the data have been distributed to researchers who have been approved by the Sample and Data Access Committee of the Biobank since 2017.

Competing interests

The authors declare that they have no competing interests.

Funding

The TMM BirThree Cohort Study was supported by the Japan Agency for Medical Research and Development (AMED), Japan [grant number, JP20km0105001]. KM was supported by a Grant-in-Aid for Early-Career Scientists (No. 18K17397) from the Ministry of Education, Culture, Sports, Science and Technology, Japan. 
Authors' contributions

KM was responsible for the study conception, design, analysis, and interpretation of the data, as well as the drafting of the manuscript. SK provided advice regarding critically important intellectual content and helped to draft the manuscript. All authors acquired the data and intensively revised the manuscript.

Acknowledgements

The authors wish to express their appreciation to the pregnant women who participated in the TMM BirThree Cohort Study.

\section{References}

1. Patra J, Bakker R, Irving H, Jaddoe VW, Malini S, Rehm J. Dose-response relationship between alcohol consumption before and during pregnancy and the risks of low birthweight, preterm birth and small for gestational age (SGA)-a systematic review and meta-analyses. 2011;118:1411-21.

2. Oei JL. Alcohol use in pregnancy and its impact on the mother and child. 2020;115:2148-63.

3. Hoyme HE, Kalberg WO, Elliott AJ, Blankenship J, Buckley D, Marais AS, et al. Updated clinical guidelines for diagnosing fetal alcohol spectrum disorders. Pediatrics. 2016;138:e20154256.

4. S. Department of Health and Human Services. U.S. Surgeon General Releases Advisory on Alcohol Use in Pregnancy. 21 February 2005. http://come-over.to/FAS/SurGenAdvisory.htm. Accessed 11 November 2020.

5. Dejong K, Olyaei A, Lo JO. Alcohol use in pregnancy. Clin Obstet Gynecol. 2019;62:142-55.

6. Popova S, Lange S, Probst C, Gmel G, Rehm J. Estimation of national, regional, and global prevalence of alcohol use during pregnancy and fetal alcohol syndrome: a systematic review and meta-analysis. Lancet Glob Health. 2017;5:e290-e299.

7. Skagerstróm J, Chang G, Nilsen P. Predictors of drinking during pregnancy: a systematic review. J Womens Health (Larchmt). 2011;20:901-13.

8. O'Keeffe LM, Kearney PM, McCarthy FP, Khashan AS, Greene RA, North RA, et al. Prevalence and predictors of alcohol use during pregnancy: findings from international multicentre cohort studies. BMJ Open. 2015;5:e006323.

9. Tamaki T, Kaneita Y, Ohida T, Harano S, Yokoyama E, Osaki Y, Takemura S, Hayashi K. Alcohol consumption behavior of pregnant women in Japan. Prev Med. 2008;47:544-9.

10. Yamamoto Y, Kaneita Y, Yokoyama E, Sone T, Takemura S, Suzuki K, et al. Alcohol consumption and abstention among pregnant Japanese women. J Epidemiol. 2008;18:173-82.

11. Ethen MK, Ramadhani TA, Scheuerle AE, Canfield MA, Wyszynski DF, Druschel CM, Romitti PA; National Birth Defects Prevention Study. Alcohol consumption by women before and during pregnancy. Matern Child Health J. 2009;13:274-85. 
12. Hutchinson D, Moore EA, Breen C, Burns L, Mattick RP. Alcohol use in pregnancy: prevalence and predictors in the Longitudinal Study of Australian Children. Drug Alcohol Rev. 2013;32:475-82.

13. Oh S, Reingle Gonzalez JM, Salas-Wright CP, Vaughn MG, DiNitto DM. Prevalence and correlates of alcohol and tobacco use among pregnant women in the United States: Evidence from the NSDUH 2005-2014. Prev Med. 2017;97:93-9.

14. Shmulewitz D, Hasin DS. Risk factors for alcohol use among pregnant women, ages $15-44$, in the United States, 2002 to 2017. Prev Med. 2019;124:75-83.

15. Murphy DJ, Dunney C, Mullally A, Adnan N, Fahey T, Barry J. A prospective cohort study of alcohol exposure in early and late pregnancy within an urban population in Ireland. Int $\mathrm{J}$ Environ Res Public Health. 2014;11:2049-63.

16. Pfinder M, Kunst AE, Feldmann R, van Eijsden M, Vrijkotte TG. Educational differences in continuing or restarting drinking in early and late pregnancy: role of psychological and physical problems. J Stud Alcohol Drugs. 2014;75:47-55.

17. Muggli E, O'Leary C, Donath S, Orsini F, Forster D, Anderson PJ, et al. "Did you ever drink more?" A detailed description of pregnant women's drinking patterns. BMC Public Health. 2016;16:683.

18. Sudhinaraset M, Wigglesworth $C$, Takeuchi DT. Social and cultural contexts of alcohol use: influences in a social-ecological framework. Alcohol Res. 2016;38:35-45.

19. Nakamura Y. Maternal and Child Health Handbook in Japan. JMAJ 2010; 53: 259-65.

20. Akashi H, Ishioka M, Hagiwara A, Akashi R, Osanai Y. Core factors promoting a continuum of care for maternal, newborn, and child health in Japan. Biosci Trends. 2018;12:1-6.

21. Ikeda A, Kawachi I, Iso H, Inoue M, Tsugane S; JPHC Study Group. Gender difference in the association between social support and metabolic syndrome in Japan: the 'enkai' effect? J Epidemiol Community Health. 2011;65:71-7.

22. Kinjo A, Kuwabara Y, Minobe R, Maezato H, Kimura M, Higuchi S, et al. Different socioeconomic backgrounds between hazardous drinking and heavy episodic drinking: Prevalence by sociodemographic factors in a Japanese general sample. Drug Alcohol Depend. 2018;193:55-62.

23. Osaki Y, Kinjo A, Higuchi S, Matsumoto H, Yuzuriha T, Horie Y, Kimura M, Kanda H, Yoshimoto H. Prevalence and trends in alcohol dependence and alcohol use disorders in Japanese adults; results from Periodical Nationwide Surveys. Alcohol Alcohol. 2016;51:465-73.

24. Kuriyama S, Metoki H, Kikuya M, Obara T, Ishikuro M, Yamanaka C, et al., Tohoku Medical Megabank Project Study Group. Cohort Profile: Tohoku Medical Megabank Project Birth and Three-Generation Cohort Study (TMM BirThree Cohort Study): Rationale, Progress and Perspective. Int J Epidemiol. 2020;49:18-

25. Kuriyama S, Yaegashi N, Nagami F, Arai T, Kawaguchi Y, Osumi N, et al., Tohoku Medical Megabank Project Study Group T, Yamamoto M. The Tohoku Medical Megabank Project: Design and Mission. J Epidemiol. 2016;26:493-

26. Atkinson, AB, Rainwater L, Smeeding TM. Income distribution in OECD countries: evidence from the Luxembourg Income Study. Paris, France: Organization for Economic Co-operation and Development; 
1995.

27. Kessler RC, Andrews G, Colpe LJ, Hiripi E, Mroczek DK, Normand SL, et al. Short screening scales to monitor population prevalences and trends in non-specific psychological distress. Psychol Med. 2002;32:959-76.

28. Furukawa TA, Kawakami N, Saitoh M, Ono Y, Nakane Y, Nakamura Y, et al. The performance of the Japanese version of the K6 and K10 in the World Mental Health Survey Japan. Int J Methods Psychiatr Res. 2008;17:152-

29. Sakurai K, Nishi A, Kondo K, Yanagida K, Kawakami N. Screening performance of K6/K10 and other screening instruments for mood and anxiety disorders in Japan. Psychiatry Clin Neurosci. 2011;65:434-

30. Brady KT, Randall CL. Gender differences in substance use disorders. Psychiatr Clin North Am. 1999;22:241-

31. Ishitsuka K, Hanada-Yamamoto K, Mezawa H, Saito-Abe M, Konishi M, Ohya Y; Japan Environment and Children's Study Group. Determinants of alcohol consumption in women before and after awareness of conception. Matern Child Health J. 2020;24:165-76.

32. Huerta MC, Borgonovi F. Education, alcohol use and abuse among young adults in Britain. Soc Sci Med. 2010;71:143-51.

33. Rosenquist JN, Murabito J, Fowler JH, Christakis NA. The spread of alcohol consumption behavior in a large social network. Ann Intern Med. 2010;152:426-

34. Glymour MM, Avendano M, Kawachi I. Socioeconomic status and health. In: Berkman LF, Kawachi I, Glymour MM, editors. Social epidemiology. New York, NY: Oxford University Press; 2014. p.17-62.

35. Grittner U, Kuntsche S, Gmel G, Bloomfield K. Alcohol consumption and social inequality at the individual and country levels - results from an international study. Eur J Public Health. 2013;23:332-

36. Organisation for Economic Co-operation and Development. Tackling harmful alcohol use: economics and public health policy. Paris, France: OECD Publishing; 2015.

37. Kitsantas P, Gaffney KF, Wu H, Kastello JC. Determinants of alcohol cessation, reduction and no reduction during pregnancy. Arch Gynecol Obstet. 2014;289:771-9.

38. McCormack C, Hutchinson D, Burns L, Wilson J, Elliott E, Allsop S, et al. Prenatal alcohol consumption between conception and recognition of pregnancy. Alcohol Clin Exp Res. 2017;41:36978.

39. Stade BC, Bailey C, Dzendoletas D, Sgro M, Dowswell T, Bennett D. Psychological and/or educational interventions for reducing alcohol consumption in pregnant women and women planning pregnancy. Cochrane Database Syst Rev 2009; (2): CD004228.

40. Cutler DM, Lleras-Muney A. Understanding differences in health behaviors by education. J Health Econ. 2010;29:1-28. 
41. Schölin L. Prevention of harm caused by alcohol exposure in pregnancy. Rapid review and case studies from Member States. Copenhagen, Denmark: WHO Regional Office for Europe; 2016.

42. Palma S, Pardo-Crespo R, Mariscal M, Perez-Iglesias R, Llorca J, Delgado-Rodríguez M. Weekday but not weekend alcohol consumption before pregnancy influences alcohol cessation during pregnancy. Eur J Public Health. 2007;17:394-

43. Corrales-Gutierrez I, Mendoza R, Gomez-Baya D, Leon-Larios F. Understanding the relationship between predictors of alcohol consumption in pregnancy: towards effective prevention of FASD. Int J Environ Res Public Health. 2020;17:1388.

44. Skagerström J, Alehagen S, Häggström-Nordin E, Årestedt K, Nilsen P. Prevalence of alcohol use before and during pregnancy and predictors of drinking during pregnancy: a cross sectional study in Sweden. BMC Public Health. 2013;13:780.

45. Denny $\mathrm{CH}$, Acero CS, Naimi TS, Kim SY. Consumption of alcohol beverages and binge drinking among pregnant women aged 18-44 Years - United States, 2015-2017. MMWR Morb Mortal Wkly Rep. 2019;68:365-

46. Sedgh G, Singh S, Hussain R. Intended and unintended pregnancies worldwide in 2012 and recent trends. Stud Fam Plann. 2014;45:301-

47. Osawa E, Ojima T, Akiyama Y, Yamagata Z. National campaign to promote maternal and child health in 21st-century Japan: Healthy Parents and Children 21. J Natl Inst Public Health. 2019;68:2-7.

48. World Health Organization. Guidelines for identification and management of substance use and substance use disorders in pregnancy. Geneva, Switzerland: World Health Organization; 2014.

\section{Tables}


Table 1. Characteristics of the pregnant women: the Tohoku Medical Megabank Project Birth and Three-Generation Cohort Study ( $\mathrm{n}=11592)$.

\begin{tabular}{|c|c|c|}
\hline & $\mathrm{n}$ & $(\%)$ \\
\hline \multicolumn{3}{|l|}{ Educational attainment } \\
\hline High school or lower & 3657 & (31.6) \\
\hline College & 4512 & (38.9) \\
\hline University or higher & 3423 & (29.5) \\
\hline \multicolumn{3}{|l|}{ Work status in early pregnancy } \\
\hline Not working & 3935 & $(34.0)$ \\
\hline Working & 7657 & $(66.0)$ \\
\hline \multicolumn{3}{|c|}{ Work status in middle pregnancy } \\
\hline Not working & 4475 & (38.6) \\
\hline Working & 7117 & $(61.4)$ \\
\hline \multicolumn{3}{|l|}{ Age in early pregnancy } \\
\hline-29 years & 3785 & (32.6) \\
\hline $30-34$ years & 4424 & $(38.2)$ \\
\hline 35- years & 3383 & $(29.2)$ \\
\hline \multicolumn{3}{|c|}{ Equivalent household income (/year) } \\
\hline 0-2 million Japanese yen & 2641 & (22.8) \\
\hline 2-3 million Japanese yen & 3669 & (31.6) \\
\hline 3-4 million Japanese yen & 2163 & $(18.7)$ \\
\hline 4- million Japanese yen & 3119 & $(26.9)$ \\
\hline \multicolumn{3}{|c|}{ Psychological distress in early pregnancy } \\
\hline No & 7695 & $(66.4)$ \\
\hline Yes & 3897 & (33.6) \\
\hline \multicolumn{3}{|c|}{ Psychological distress in middle pregnancy } \\
\hline No & 8373 & $(72.2)$ \\
\hline Yes & 3219 & $(27.8)$ \\
\hline \multicolumn{3}{|l|}{ Alcohol use in early pregnancy } \\
\hline No & 9171 & $(79.1)$ \\
\hline Yes & 2421 & $(20.9)$ \\
\hline \multicolumn{3}{|c|}{ Alcohol use in middle pregnancy } \\
\hline No & 10849 & (93.6) \\
\hline Yes & 743 & (6.4) \\
\hline
\end{tabular}


Table 2. Associations of education and work status with alcohol use in early pregnancy.

Alcohol use in (\%) Age-adjusted $\quad$ Multivariable-adjusted $^{\mathrm{a}}$ early pregnancy OR $(95 \% \mathrm{CI}) \quad P$-value $\quad$ OR $(95 \% \mathrm{CI}) \quad P$-value /participants

Total $2421 / 11592$ $(20.9)$

Educational

attainment
High school or
$588 / 3657$
(16.1) 1.00
1.00

lower

$\begin{array}{llllllllll}\text { College } & 986 / 4512 & (21.9) & 1.44 & (1.29-1.61) & <0.001 & 1.33 & (1.18-1.49) & <0.001 \\ \text { University or } & 847 / 3423 & (24.7) & 1.69 & (1.50-1.91) & <0.001 & 1.47 & (1.30-1.66) & <0.001\end{array}$

higher

Work status in

early pregnancy

\begin{tabular}{lcccccccc} 
Not working & $616 / 3935$ & $(15.7)$ & 1.00 & \multicolumn{5}{c}{1.00} \\
Working & $1805 / 7657$ & $(23.6)$ & 1.67 & $(1.51-1.84)$ & $<0.001$ & 1.53 & $(1.38-1.70)$ & $<0.001$
\end{tabular}

Age in early

pregnancy

\begin{tabular}{lllllllll}
-29 & years & $726 / 3785$ & $(19.2)$ & 1.00 & \multicolumn{7}{c}{1.00} \\
30-34 years & $948 / 4424$ & $(21.4)$ & 1.15 & $(1.03-1.28)$ & 0.01 & 1.08 & $(0.96-1.20)$ & 0.19 \\
35- years & $747 / 3383$ & $(22.1)$ & 1.19 & $(1.07-1.34)$ & 0.002 & 1.11 & $(0.99-1.25)$ & 0.09
\end{tabular}

Equivalent

household income

(/year)
0-2 million
$409 / 2641$
(15.5) 1.00
1.00

Japanese yen

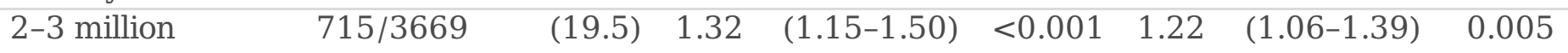

Japanese yen

3-4 million

$534 / 2163$

$(24.7)$

1.78

$(1.54-2.05)<0.001 \quad 1.50 \quad(1.30-1.74)<0.001$

Japanese yen

4- million

$763 / 3119$

(24.5) 1.74

Japanese yen

Psychological

distress in early

pregnancy

\begin{tabular}{lcccccccc} 
No & $1647 / 7695$ & $(21.4)$ & 1.00 & \multicolumn{5}{c}{1.00} \\
Yes & $774 / 3897$ & $(19.9)$ & 0.92 & $(0.84-1.02)$ & 0.10 & 0.95 & $(0.86-1.04)$ & 0.26 \\
\hline
\end{tabular}

CI, confidence interval; OR, odds ratio.

adjusted for all other variables in the table. 
Table 3. Associations of education and work status with alcohol use in middle pregnancy.

Alcohol use in (\%) $\quad$ Age-adjusted $\quad$ Multivariable-adjusted $^{\mathrm{a}}$

middle pregnancy /participants

$743 / 11592$

$(6.4)$

Total

Educational

attainment

High school or

lower

$\begin{array}{lllllllll}\text { College } & 303 / 4512 & (6.7) & 1.06 & (0.89-1.27) & 0.52 & 1.06 & (0.88-1.27) & 0.57 \\ \text { University or } & 213 / 3423 & (6.2) & 0.98 & (0.81-1.19) & 0.83 & 0.95 & (0.77-1.17) & 0.63\end{array}$

higher

Work status in

middle pregnancy

\begin{tabular}{lllllllll} 
Not working & $237 / 4475$ & $(5.3)$ & 1.00 & \multicolumn{7}{c}{1.00} \\
Working & $506 / 7117$ & $(7.1)$ & 1.37 & $(1.17-1.60)$ & 0.0001 & 1.38 & $(1.18-1.63)$ & $<0.001$
\end{tabular}

Age in early

pregnancy

\begin{tabular}{lclllllll}
-29 years & $217 / 3785$ & $(5.7)$ & 1.00 & \multicolumn{7}{c}{1.00} \\
\hline $30-34$ years & $281 / 4424$ & $(6.4)$ & 1.12 & $(0.93-1.34)$ & 0.24 & 1.12 & $(0.93-1.35)$ & 0.22 \\
\hline $35-$ years & $245 / 3383$ & $(7.2)$ & 1.28 & $(1.06-1.55)$ & 0.01 & 1.30 & $(1.07-1.57)$ & 0.009
\end{tabular}

Equivalent

household income

(/year)
0-2 million
$172 / 2641$
(6.5) 1.00
1.00

Japanese yen

2-3 million

$229 / 3669$

(6.2) $0.95 \quad(0.77-1.16)$

0.61

0.94

(0.77-1.16)

0.56

Japanese yen

3-4 million

Japanese yen

4- million

$121 / 2163$

(5.6) $0.84 \quad(0.66-1.07)$

0.15

0.8

(0.63-1.02)

0.08

$221 / 3119$

(7.1) $1.05 \quad(0.86-1.30)$

$0.63 \quad 1.00 \quad(0.80-1.26)$

0.98

Japanese yen

Psychological

distress in middle

pregnancy

\begin{tabular}{lllllllll} 
No & $518 / 8373$ & $(6.2)$ & 1.00 & & & 1.00 & & \\
Yes & $225 / 3219$ & $(7.0)$ & 1.16 & $(0.99-1.37)$ & 0.07 & 1.18 & $(1.00-1.39)$ & 0.05 \\
\hline
\end{tabular}

CI, confidence interval; OR, odds ratio.

adjusted for all other variables in the table. 
Table 4. Associations education and work status with alcohol cessation between early and middle pregnancy among women who consumed alcohol in early pregnancy.

\begin{tabular}{|c|c|c|c|c|c|c|c|}
\hline & \multirow{2}{*}{$\begin{array}{l}\text { Alcohol } \\
\text { cessation } \\
\text { /drinkers in } \\
\text { early } \\
\text { pregnancy }\end{array}$} & \multirow[t]{2}{*}{ (\%) } & \multicolumn{3}{|c|}{ Age-adjusted } & \multicolumn{2}{|c|}{ Multivariable-adjusted ${ }^{\mathrm{a}}$} \\
\hline & & & \multicolumn{2}{|c|}{ OR $(95 \%$ CI) } & \multirow[t]{2}{*}{$P$-value } & OR $(95 \%$ CI $)$ & $P$-value \\
\hline Total & $1881 / 2421$ & $(77.7)$ & & & & & \\
\hline \multicolumn{8}{|l|}{$\begin{array}{l}\text { Educational } \\
\text { attainment }\end{array}$} \\
\hline $\begin{array}{l}\text { High school or } \\
\text { lower }\end{array}$ & $435 / 588$ & $(74.0)$ & 1.00 & & & 1.00 & \\
\hline College & $769 / 986$ & (78.0) & 1.26 & $(0.99-1.60)$ & 0.06 & $(0.91-1.49)$ & 0.23 \\
\hline $\begin{array}{l}\text { University or } \\
\text { higher }\end{array}$ & $677 / 847$ & (79.9) & 1.40 & $(1.09-1.80)$ & 0.008 & $(1.00-1.71)$ & 0.05 \\
\hline \multicolumn{8}{|l|}{$\begin{array}{l}\text { Changes in work } \\
\text { status during } \\
\text { pregnancy }\end{array}$} \\
\hline $\begin{array}{l}\text { Not working in } \\
\text { early and middle } \\
\text { pregnancy }\end{array}$ & $465 / 616$ & $(75.5)$ & 1.00 & & & 1.00 & \\
\hline $\begin{array}{l}\text { Working only in } \\
\text { early pregnancy }\end{array}$ & $110 / 130$ & $(84.6)$ & 1.76 & $(1.06-2.94)$ & 0.03 & $(1.03-2.88)$ & 0.04 \\
\hline $\begin{array}{l}\text { Working in early } \\
\text { and middle } \\
\text { pregnancy }\end{array}$ & $1306 / 1675$ & $(78.0)$ & 1.14 & $(0.92-1.42)$ & 0.23 & $(0.87-1.36)$ & 0.46 \\
\hline \multicolumn{8}{|l|}{$\begin{array}{l}\text { Age in early } \\
\text { pregnancy }\end{array}$} \\
\hline-29 years & $566 / 726$ & (78.0) & 1.00 & & & 1.00 & \\
\hline $30-34$ years & $753 / 948$ & (79.4) & 1.09 & $(0.86-1.38)$ & 0.47 & $(0.85-1.38)$ & 0.51 \\
\hline 35 - years & $562 / 747$ & $(75.2)$ & 0.86 & $(0.67-1.09)$ & 0.22 & $(0.67-1.10)$ & 0.24 \\
\hline
\end{tabular}

Equivalent

household income

(/year)
$0-2$ million
$290 / 409 \quad(70.9) \quad 1.00$
1.00

Japanese yen

2-3 million

Japanese yen

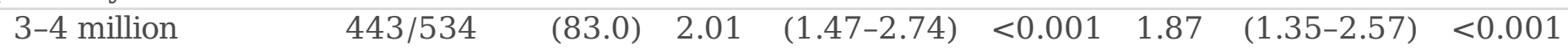

Japanese yen
4- million
$591 / 763$
(77.5) $\quad 1.44$
$(1.10-1.90) \quad 0.009$
$1.31 \quad(0.97-1.76)$
0.08

Japanese yen

Changes in

psychological

distress during

pregnancy

None in early

1130/1453

(77.8) $\quad 1.00$

1.00

and middle

pregnancy

Only in early pregnancy

Only in middle

$250 / 319$

(78.4) 1.03

(0.76-1.38)

0.87

1.03

(0.77-1.39)

$143 / 194$

(73.7)

$0.80 \quad(0.57-1.13)$

0.20

0.80

$\begin{array}{ll}(0.57-1.13) & 0.21\end{array}$ 
pregnancy

$\begin{array}{lllllllll}\text { Both in early } & 358 / 455 & (78.7) & 1.04 & (0.81-1.35) & 0.76 & 1.07 & (0.83-1.39) & 0.60\end{array}$

and middle

pregnancy

CI, confidence interval; OR, odds ratio.

adjusted for all other variables in the table.

\section{Figures}

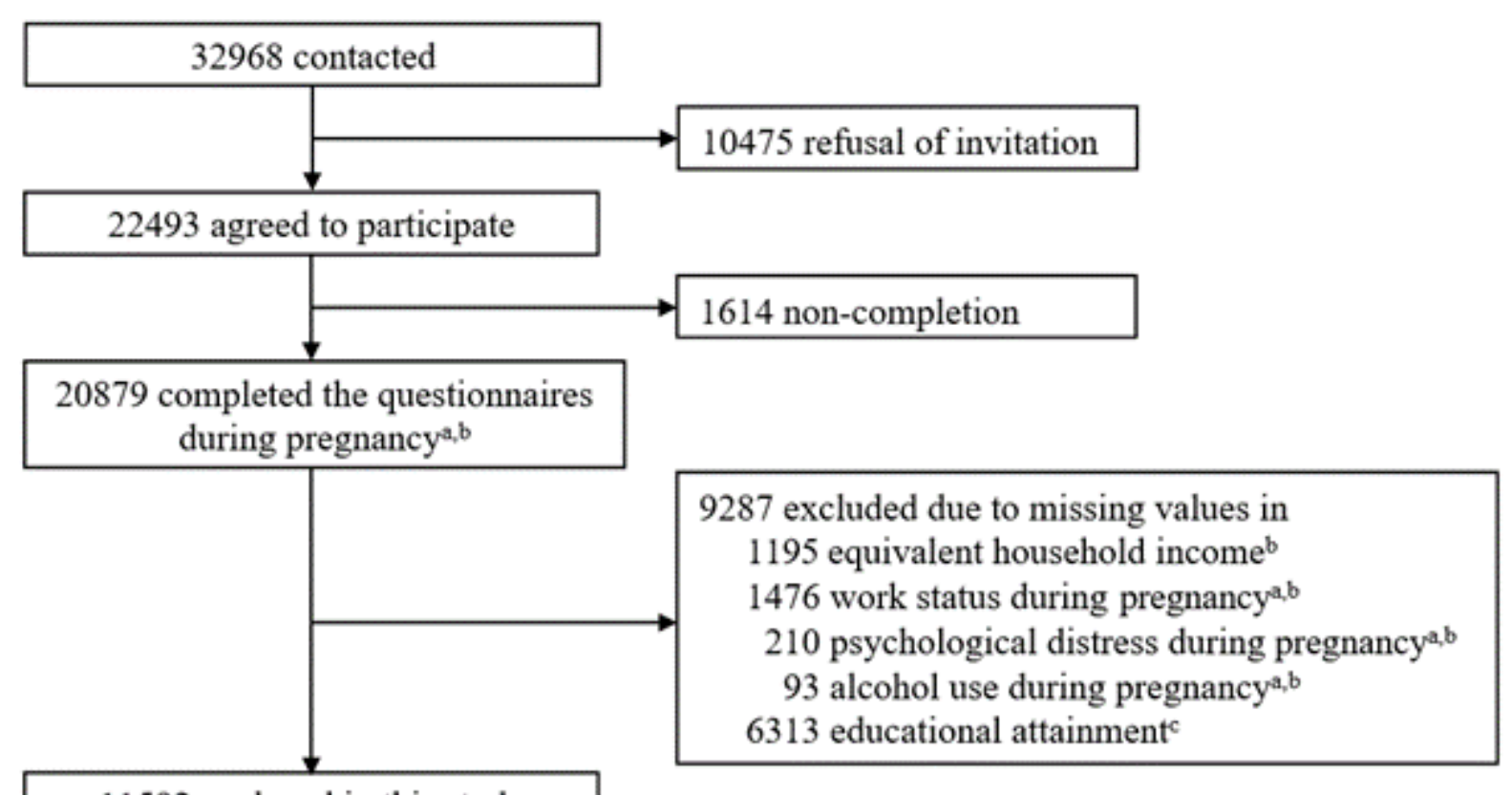

11592 analyzed in this study

\section{Figure 1}

Flow diagram of participants in the present analysis of the TMM BirThree Cohort Study aData on work status, psychological distress, and alcohol use were obtained using a questionnaire administered in early pregnancy. bData on equivalent household income, work status, psychological distress, and alcohol use were obtained using a questionnaire administered in middle pregnancy. cData on educational attainment were obtained using a questionnaire administered one year postpartum. 


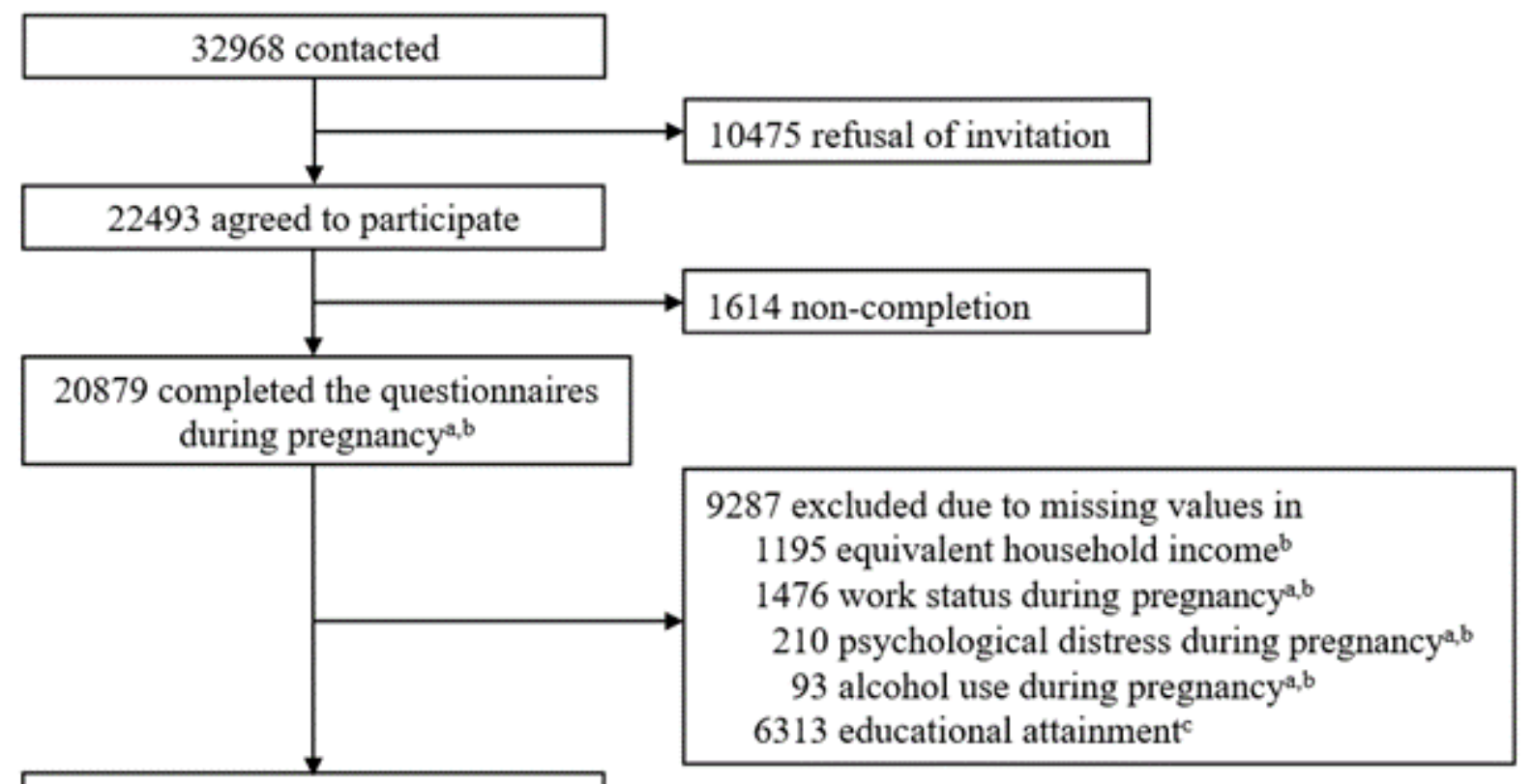

11592 analyzed in this study

\section{Figure 1}

Flow diagram of participants in the present analysis of the TMM BirThree Cohort Study aData on work status, psychological distress, and alcohol use were obtained using a questionnaire administered in early pregnancy. bData on equivalent household income, work status, psychological distress, and alcohol use were obtained using a questionnaire administered in middle pregnancy. cData on educational attainment were obtained using a questionnaire administered one year postpartum.

\section{Supplementary Files}

This is a list of supplementary files associated with this preprint. Click to download.

- 4.BirThreealcoholR1 supple201118submit.docx

- 4.BirThreealcoholR1 supple201118submit.docx 